SMOKING

\title{
Long term smoking with age builds up excessive oxidative stress in bronchoalveolar lavage fluid
}

\author{
K Nagai, T Betsuyaku, T Kondo, Y Nasuhara, M Nishimura

See end of article for authors' affiliations

.....................

Correspondence to: Dr T Betsuyaku, First Department of Medicine, Hokkaido University School of Medicine, N-15, W-7, Kita-ku, Sapporo, Japan 060-8638;

byłomoko@med.hokudai.

ac.jp

Received 7 July 2005

Accepted 17 January 2006

Published Online First

14 March 2006

\begin{abstract}
Background: Epithelial lining fluid plays a critical role in protecting the lung from oxidative stress, in which the oxidised status may change by ageing, smoking history, and pulmonary emphysema.

Methods: Bronchoalveolar lavage (BAL) was performed on 109 young and older subjects with various smoking histories. The protein carbonyls, total and oxidised glutathione were examined in BAL fluid.

Results: By Western blot analysis, the major carbonylated protein in the BAL fluid was sized at $68 \mathrm{kDa}$, corresponding to albumin. The amount of carbonylated albumin per $\mathrm{mg}$ total albumin in BAL fluid was four times higher in older current smokers and three times higher in older former smokers than in age matched non-smokers ( $p<0.0001, p=0.0003$, respectively), but not in young smokers. Total glutathione in BAL fluid was significantly increased both in young $(p=0.006)$ and older current smokers $(p=0.0003)$ compared with age matched non-smokers. In contrast, the ratio of oxidised to total glutathione was significantly raised $(72 \%)$ only in older current smokers compared with the other groups. There was no significant difference in these parameters between older smokers with and without mild emphysema.

Conclusions: Oxidised glutathione associated with excessive protein carbonylation accumulates in the lung of older smokers with long term smoking histories even in the absence of lung diseases, but they are not significantly enhanced in smokers with mild emphysema.
\end{abstract}

$\mathrm{T}$ he lung is an organ constantly exposed to exogenous oxidants such as cigarette smoke and air pollutants. Epithelial lining fluid (ELF) acts as an interface between the airspace epithelium and the external environment and therefore affords protection against epithelial cell injury. ${ }^{1}$ Because the constituents of ELF form the primary targets of inhaled oxidant pollutants and also inflammatory reactive oxygen species (ROS) generated within the alveolar space, the oxidative modifications of certain extracellular targets and their functional consequences have received considerable attention. ${ }^{2}$ It is known that protein carbonylation reflects the oxidation of Lys, Arg, or Pro residues in proteins. The content of protein carbonyls is therefore by far the most commonly used marker for protein oxidation. ${ }^{3}$

On the other hand, there are various kinds of extracellular antioxidants in the lungs such as mucin, uric acid, ascorbic acid, $\alpha$-tocopherol, glutathione, antioxidant enzymes and proteins that are capable of binding metals. Glutathione is a sulfhydryl-containing tripeptide (L-gamma-glutamyl-Lcysteinyl-glycine) that is present in high concentrations in all cells and protects against intracellular oxidants and xenobiotics. ${ }^{4}$ Extracellular glutathione can be augmented by cellular sources from respiratory tract epithelial cells and inflammatory cells such as macrophages. The levels of glutathione in ELF are 100-fold higher than in plasma, which may indicate its relative importance among the various antioxidants. ${ }^{45}$

The elderly are particularly vulnerable to smoking associated respiratory diseases. Worldwide, the ratio of smokers is still high among the middle aged or elderly population, and they usually have long term smoking histories. Cigarette smoking is a major risk factor for the development of emphysema, and it normally affects patients in the fifth to sixth decade of life. Although an oxidant/antioxidant imbalance has been implicated in the development of emphysema, ${ }^{6}$ there is still a large gap in our understanding of the link between the cumulative effects of ageing and decades of continuous smoking on the oxidative stress and antioxidant mechanisms in the lung. Total glutathione is known to be raised in the bronchoalveolar lavage (BAL) fluid of recent young smokers, and the majority $(>95 \%)$ of the total glutathione is maintained in the reduced state. ${ }^{5}$ However, there is a lack of information on the levels and redox state of glutathione in the BAL fluid of older smokers with or without pulmonary emphysema.

We therefore investigated whether chronic smoking induced changes in protein carbonylation and glutathione redox status in BAL fluid differ by age, duration of smoking, or the presence of emphysema. BAL was performed to obtain ELF from lifelong non-smokers as well as young and older smokers with various smoking histories.

\section{METHODS \\ Subjects}

A total of 109 community based asymptomatic volunteers were recruited from the patients in our smoking cessation and non-pulmonary clinics and from the employees and students in our medical school. Most of the subjects had taken part in previous studies in our laboratory. ${ }^{7}$ The young group (age 20-29 years, $\mathrm{n}=39$ ) consisted of 16 lifelong nonsmokers and 23 current smokers who had smoked for less than 3 years. The older group (age 37-77 years, $\mathrm{n}=70$ ) included seven lifelong non-smokers, 17 former smokers, and 46 current smokers with smoking histories of more than 20 years. Former smokers were arbitrarily defined as people who had quit smoking for at least 1 year. None of the subjects was on regular medication or had a history of asthma or other allergic disorders. All subjects had been free of clinically apparent respiratory infections for the preceding 2 months and had been evaluated by physical examination, chest radiography, and a blood test. After elimination of non-

Abbreviations: BAL, bronchoalveolar lavage; DNP dinitrophenylhydrazine; ELF, epithelial lining fluid; $\mathrm{FEV}_{1}$, forced expiratory volume in 1 second; GSH, reduced glutathione; GSSG, glutathione disulfide 
eligible subjects, all older former and current smokers were screened for emphysematous changes by high resolution computed tomographic (HRCT) scanning as previously described. ${ }^{9}$ Pulmonary function tests were performed in accordance with the standard techniques of the American Thoracic Society. Forced expiratory volume in l second $\left(\mathrm{FEV}_{1}\right)$ from the flow-volume curve was expressed as a percentage of the predicted value according to the equations of Berglund et al. ${ }^{10}$

All of the subjects provided written informed consent and the study was approved by the ethics committee of Hokkaido University School of Medicine.

\section{Sequential BAL}

Sequential BAL was performed through a wedged flexible fibreoptic bronchoscope (Olympus BF-B3R, Tokyo, Japan) as described previously. ${ }^{9}$ The fluid returned from the first $50 \mathrm{ml}$ aliquot was not used in the study. The remaining lavage fluid was pooled and used as the BAL fluid. Differential cell counts were performed as previously described. ${ }^{9}$ The level of total protein in the BAL fluid was determined using a Micro BCA Protein Assay Reagent kit (Pierce Biotech, IL, USA). The level of albumin was quantified by laser nephelometry as described previously. ${ }^{9}$ The level of transferrin was measured using the human transferrin enzyme linked immunosorbent assay quantification kit (Bethyl Laboratories Inc, TX, USA).

\section{Assessment of protein carbonyls in BAL fluid}

Oxidation of individual BAL fluid proteins was measured by analysis of Western blots according to the method of Shacter et al. ${ }^{11}$ BAL fluid was derivatised with dinitrophenylhydrazine (DNP) using the OxyBlot Protein Oxidation Detection kit (Chemicon International, Temecula, CA, USA) with slight modification. Briefly, $16 \mu \mathrm{l}$ of unconcentrated BAL fluid were denatured by adding $3 \mu \mathrm{l}$ of $20 \%$ sodium dodecylsulfate (SDS)-polyacrylamide, derivatised by adding $1 \mu \mathrm{l} 10 \mathrm{X}$ DNPH solution, and neutralised by adding $7.5 \mu$ l neutralization solution and $1.5 \mu \mathrm{l} 2$-mercaptoethanol. Samples were separated by electrophoresis on $10 \%$ SDS-polyacrylamide electrophoresis gels. Blots were performed using the anti-DNP antibody and scanned with a GT-9500 scanner (Epson, Nagano, Japan); the intensity of the bands was calculated using NIH Image software (version 1.62). On each blot the recorded total DNP intensity of all bands detected for each lane was divided by that of a standard sample from a representative young non-smoker. The total carbonyl content in the BAL fluid was referred as total DNP units/ml BAL fluid. The assay for the total carbonyl content had an intrabatch coefficient of variation of $12 \%(\mathrm{n}=7)$ and an interbatch coefficient of variation of $16 \%(n=5)$.
The molecular masses of albumin and transferrin were determined by Western blotting on the same membrane used for the Oxyblot. Specifically, after the Western blot for carbonyl proteins, the anti-DNP antibody was removed, then incubated with 1:1000 peroxidase conjugated anti-human albumin antibody (DAKO, Glostrup, Denmark) or 1:1000 rabbit anti-human transferrin (Dakocytomation, Glostrup, Denmark) followed by 1:15000 horseradish peroxidase conjugated goat anti-rabbit antibody (DAKO). Sites of antibody binding were visualised using the ECL ${ }^{\text {Plus }}$ Western blotting detection system (Amersham, Aylesbury, UK).

\section{Measurement of total glutathione and glutathione disulfide in BAL fluid}

Total glutathione and glutathione disulfide (GSSG), oxidised glutathione, were measured in all samples using a glutathione assay kit (Cayman Chemical Co, MI, USA) as described by Tietze and co-workers. ${ }^{12}$ The assays for total glutathione and GSSG had intrabatch coefficients of variation of $3 \%(\mathrm{n}=12)$ and $3 \%(\mathrm{n}=10)$, respectively, and interbatch coefficients of variation of $6 \%(n=10)$ and $13 \%$ $(\mathrm{n}=8)$, respectively.

\section{Statistical analyses}

Differences between the two means were performed with a two tailed unpaired Student's $t$ test using Statview Software (SAS Institute Inc, NC, USA). More than two means were compared by analysis of variance followed by the GamesHowell method using SAS software Version 8.2 (SAS Institute Inc). A value of $\mathrm{p}<0.05$ was considered to be statistically significant. The results are reported as standard error of the mean (SE).

\section{RESULTS}

\section{Characteristics of subjects}

Clinical characteristics and pulmonary function data for the subjects are summarised in table 1. Emphysema, as detected on CT scans, was less than $25 \%$ of the total lung area in most subjects categorised in the emphysema groups. There was no difference in the number of cigarettes smoked per day between young and older current smokers.

\section{BAL findings}

BAL findings are shown in table 2. The total protein, albumin, and transferrin levels in BAL fluid from young smokers were significantly lower than those from young nonsmokers. There were no differences in the levels of total protein, albumin, and transferrin in BAL fluid among older groups. The numbers of total cells and macrophages in BAL fluid were significantly increased in current smokers

Table 1 Characteristics of subjects

\begin{tabular}{|c|c|c|c|c|c|c|c|}
\hline & \multicolumn{3}{|l|}{ Young } & \multicolumn{4}{|l|}{ Older } \\
\hline & \multirow{2}{*}{$\begin{array}{l}\text { Non- } \\
\text { smokers }\end{array}$} & \multirow{2}{*}{$\begin{array}{l}\text { Current } \\
\text { smokers }\end{array}$} & \multirow{2}{*}{$\begin{array}{l}\text { Non- } \\
\text { smokers }\end{array}$} & \multicolumn{2}{|l|}{ Former smokers } & \multicolumn{2}{|l|}{ Current smokers } \\
\hline & & & & No emphysema & Emphysema & No emphysema & Emphysema \\
\hline No of subjects & 16 & 23 & 7 & 7 & 10 & 21 & 25 \\
\hline Age (years) & $23(1)$ & $23(0)$ & $63(3)$ & $65(2)$ & $59(3)$ & $57(2)$ & $61(2)$ \\
\hline Cigarettes/day & 0 & $20(1)$ & 0 & 0 & 0 & 27 (5) & $25(4)$ \\
\hline Pack-years & 0 & $5(1)$ & 0 & $35(10)$ & $41(7)$ & $55(5)$ & $45(4)$ \\
\hline VC (\% pred) & $97(3)$ & $96(3)$ & $122(8)$ & $125(3)$ & $110(3) \dagger$ & $110(4)$ & $110(4)$ \\
\hline $\mathrm{FEV}_{1}$ (\% pred) & $83(3)$ & $88(3)$ & $124(8)$ & $129(5)$ & $97(5) \dagger$ & $101(5)$ & $92(4) \ddagger$ \\
\hline $\mathrm{FEV}_{1}$ /FVC (\%) & $91(2)$ & $88(2)$ & $84(2)$ & $80(2)$ & $73(3)^{*}$ & $79(2)$ & $70(2)^{*} \ddagger$ \\
\hline
\end{tabular}

VC, vital capacity; $\mathrm{FEV}_{1}$, forced expiratory volume in 1 second; FVC, forced vital capacity

Data are expressed as mean (SE).

*Significantly different from older non-smokers $(p<0.05)$.

†Significantly different from older former smokers without emphysema $(p<0.05)$

$\ddagger$ Significantly different from older current smokers without emphysema $(p<0.05)$. 
Table 2 BAL fluid findings

\begin{tabular}{|c|c|c|c|c|c|c|c|}
\hline & \multicolumn{2}{|l|}{ Young } & \multicolumn{5}{|l|}{ Older } \\
\hline & \multirow{2}{*}{$\begin{array}{l}\text { Non- } \\
\text { smokers }\end{array}$} & \multirow{2}{*}{$\begin{array}{l}\text { Current } \\
\text { smokers }\end{array}$} & \multirow{2}{*}{$\begin{array}{l}\text { Non- } \\
\text { smokers }\end{array}$} & \multicolumn{2}{|l|}{ Former smokers } & \multicolumn{2}{|l|}{ Current smokers } \\
\hline & & & & No emphysema & Emphysema & No emphysema & Emphysema \\
\hline Recovery rate (\%) & $74(4)$ & $64(3)^{*}$ & $71(4)$ & $54(5)$ & $33(5) \dagger \ddagger$ & $50(4) \dagger$ & $33(5) \dagger \S$ \\
\hline Albumin (mg/l) & $47(7)$ & $33(3)^{*}$ & $55(9)$ & 57 (11) & 59 (11) & $32(2)$ & $50(10)$ \\
\hline Total protein (mg/l) & $116(14)$ & $92(7)^{*}$ & $160(22)$ & $128(28)$ & $210(44)$ & $111(10)$ & $142(13)$ \\
\hline Transferrin (mg/l) & $3.8(0.4)$ & $2.9(0.2)^{*}$ & $7.4(2.0)$ & $4.3(1.2)$ & $4.5(1.1)$ & $3.9(0.4)$ & $3.6(0.3)$ \\
\hline Total cells $\left(\times 10^{-4} / \mathrm{ml}\right)$ & $8.1(0.9)$ & $20.1(2.2)^{*}$ & $13.4(1.3)$ & $9.6(2.4)$ & $10.5(3.4)$ & $27.3(4.3) \dagger$ & $36(8.2) \dagger$ \\
\hline Macrophages $\left(\times 10^{-4} / \mathrm{ml}\right)$ & $6.9(0.9)$ & $19.5(2.1)^{*}$ & $10.8(1.3)$ & $8.0(1.9)$ & $8.4(2.4)$ & $25.9(4.1) \dagger$ & $32.9(8.0) \dagger$ \\
\hline Neutrophils $\left(\times 10^{-4} / \mathrm{ml}\right)$ & $0.20(0.05)$ & $0.24(0.08)$ & $0.04(0.01)$ & $0.05(0.01)$ & $0.06(0.02)$ & $0.62(0.45)$ & $0.59(0.25)$ \\
\hline
\end{tabular}

Data are expressed as mean (SE).

*Significantly different from young non-smokers $(p<0.05)$.

$\uparrow$ Significantly different from older non-smokers $(p<0.05)$.

$\ddagger$ Significantly different from older former smokers without emphysema $(p<0.05)$.

$\S$ Significantly different from older smokers without emphysema $(p<0.05)$.

compared with non-smokers, both in young and older groups. The percentage of macrophages and neutrophils in BAL fluid did not differ between young and older current smokers.

\section{Total protein carbonyls in BAL fluid}

The immunoblot analysis demonstrated a major carbonyl protein band for all of the subjects with a molecular weight of $68 \mathrm{kDa}$ (fig lA and B) and a faint band of $80 \mathrm{kDa}$ for most of the subjects. These bands were speculated to be albumin and transferrin, respectively, based on removal of the anti-DNP antibody followed by Western blotting with antibodies against human albumin or human transferrin (fig 2). As shown in fig 3, the total DNP in units/ml BAL fluid from older current and former smokers was significantly higher than in lifelong non-smokers of the same age $(1.72(0.18)$ and 1.81 (0.24) $v 0.7$ (0.29) unit $/ \mathrm{ml} ; \mathrm{p}=0.0028$ and $\mathrm{p}=0.0078$, respectively). In contrast, no difference was found in the total DNP units/ml BAL fluid between non-smokers and current smokers among the young subjects (1.05 (0.14) $v 1.0$ (0.09) units $/ \mathrm{ml}, \mathrm{p}=0.82$ ). There was also no difference between former smokers with and without emphysema $(2.16(0.34) \vee v 1.32(0.22)$ units $/ \mathrm{ml}, \mathrm{p}=0.08)$ or between current smokers with and without emphysema $(2.00(0.31) v$ 1.44 (0.14) units/ml, $\mathrm{p}=0.15$ ).

\section{Albumin carbonylation in BAL fluid}

To focus on the carbonylation of albumin, DNP units of the $68-\mathrm{kDa}$ band (corresponding to albumin) were quantified. The value was normalised according to the concentration of albumin in the BAL fluid (fig 4). The ratio of carbonylated albumin per mg total albumin was four times higher in older current smokers and three times higher in older former smokers than in age matched lifelong non-smokers (fig 4). In contrast, there was no difference in the ratio of albumin carbonylation in BAL fluid between young smokers and nonsmokers $(p=0.21)$. In both current and former smokers there was no difference in the ratio of albumin carbonylation between the subjects with and without emphysema.

\section{Total glutathione and GSSG in BAL fluid}

Total glutathione was detected in unconcentrated BAL fluid for all subjects (fig 5). The concentration of total glutathione in BAL fluid was significantly increased in smokers compared with non-smokers, even in young subjects (3.11 (0.4) $v 1.17$ (0.33) $\mu \mathrm{g} / \mathrm{ml}, \mathrm{p}=0.006)$. It was also significantly increased in older current smokers compared with age matched nonsmokers and former smokers $(2.64(0.34) \vee 0.89(0.19)$ and $0.88(0.29) \mu \mathrm{g} / \mathrm{ml}, \mathrm{p}=0.0003$ and $\mathrm{p}=0.0014$, respectively). In contrast, the level of GSSG was markedly raised only in older current smokers (1.38 $(0.2) \mu \mathrm{g} / \mathrm{ml})$ and was mostly

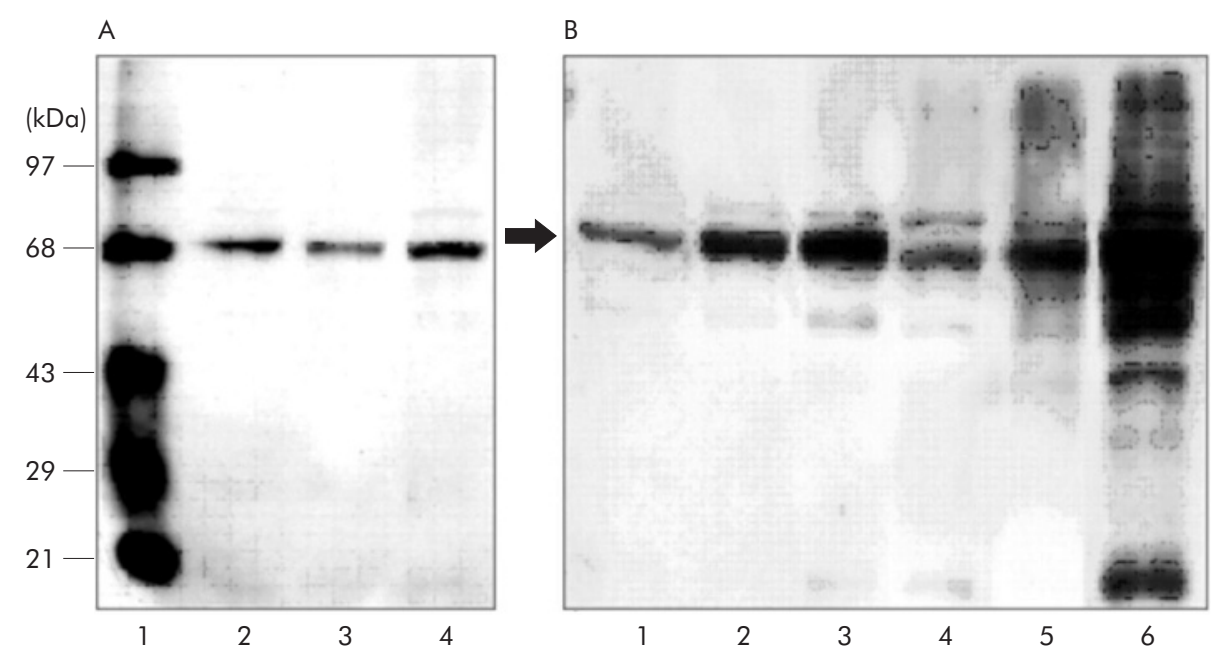

Figure 1 Representative Western blots of oxidised protein in BAL fluid. (A) Representative Western blots from young subjects. Lane 1, molecular weight protein standards in which the second band from the top $(68 \mathrm{kDa})$ is bovine serum albumin; lane 2, a young non-smoker; lane 3, a young current smoker; lane 4, a young non-smoker which was used as a standard for each blot. (B) Representative blots from older subjects. Lane 1 , standard BAL sample also shown in lane 4 of (A); lanes 2 and 3, older current smokers without emphysema; lane 4, older non-smoker; lanes 5 and 6, older current smokers with emphysema. 


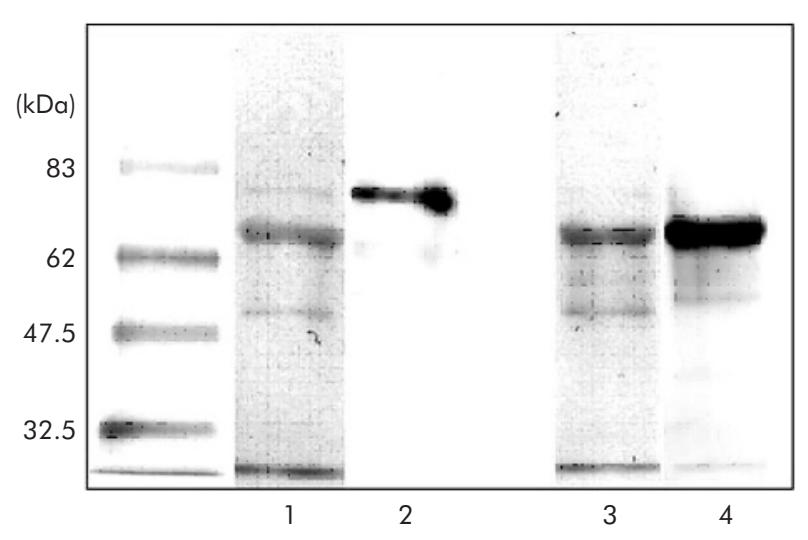

Figure 2 Immunoblots for transferrin and albumin in BAL fluid. After removal of the anti-DNP antibody, Western blotting was carried out on the same membrane. Lanes 1 and 3, anti-DNP antibody; lane 2, antihuman transferrin antibody; lane 4, anti-human albumin antibody. The positions of the molecular weight standards are shown on the left.

under the detection limit in the other groups (fig 6). No significant difference was observed between former or current smokers with and without emphysema either in the level of total glutathione in BAL fluid (former smokers: 1.15 (0.47) $v 0.49(0.12) \mu \mathrm{g} / \mathrm{ml}, \mathrm{p}=0.23$; current smokers: 2.78 $(0.55) v 2.46(0.38) \mu \mathrm{g} / \mathrm{ml}, \mathrm{p}=0.64)$ or in the level of GSSG in BAL fluid (former smokers: $0.28(0.13) v 0.09(0.05) \mu \mathrm{g} / \mathrm{ml}$, $\mathrm{p}=0.27$; current smokers: $1.48(0.38) v 1.28(0.26) \mu \mathrm{g} / \mathrm{ml}$, $\mathrm{p}=0.67$, respectively). The ratio of GSSG per total glutathione in older current smokers was as high as 0.72 and was significantly higher than in the other groups (fig 7).

\section{DISCUSSION}

In this study we have shown that older smokers with a long term history of smoking have excessive protein carbonyls and accumulate GSSG in BAL fluid, indicating that endogenous antioxidant defences are overwhelmed. Based on the number of cigarettes smoked per day, the amount of exogenous ROS from cigarette smoke was similar for all current smokers regardless of their age; however, the young and older current smokers undoubtedly developed different levels of oxidative stress in the lungs. On the other hand, ageing alone did not affect the level of protein carbonyls, total glutathione, or GSSG in BAL fluid.
The reaction of ROS with proteins results in the formation of carbonyl groups on amino acid residues. Oxidative stress overwhelming the antioxidant defence of the lung may lead to lung injury through a variety of mechanisms including lipid peroxidation of epithelial cell membranes. ${ }^{13}{ }^{14}$ Total protein carbonyls are reportedly increased in the BAL fluid from patients with acute respiratory distress syndrome, ${ }^{15}$ idiopathic pulmonary fibrosis, sarcoidosis, asbestosis, ${ }^{16}$ and cystic fibrosis. ${ }^{17}$ Notably, we found in this study that the level of total protein carbonyls in BAL fluid was raised not only in older current smokers but also in older former smokers despite not smoking for at least a year, indicating that the mechanisms responsible for increased protein carbonyls associated with smoking persist after cessation.

To clarify how protein oxidation participates in pathogenic processes, it will be important to identify the organ and/or disease specific proteins that are most susceptible to oxidative modification and the functional effects of their oxidation. Albumin and transferrin in the serum of mice and albumin and $\alpha_{1}$-macroglobulin in the serum of rats accrue significant levels of carbonylation. ${ }^{18}$ In the plasma of humans, albumin, fibrinogen, and both fibrinogen $\gamma$-chain and $\alpha_{1}$-antitrypsin precursors are major targets for carbonylation in uraemia, ${ }^{19}$ lung cancer, $^{20}$ and Alzheimer's disease, ${ }^{21}$ respectively. We report here for the first time that the oxidation of albuminthe most abundant protein in BAL fluid-mostly accounts for excessive total protein carbonylation in older smokers. It is plausible that albumin in BAL fluid from older current smokers may lose its functional efficiency as a consequence of carbonylation because oxidative modifications of albumin reportedly attenuate its antioxidative capacity. ${ }^{22}$

Glutathione also functions as an extracellular antioxidant of the lungs by preventing the oxidation of functional surfactants and antioxidant enzymes only in its reduced form (GSH). ${ }^{53} \mathrm{GSH}$ inhibits protein carbonyl formation in plasma following exposure to cigarette smoke. ${ }^{24}$ Although the concentration of total glutathione in BAL fluid is known to vary between lung diseases, the presence of its oxidised form in BAL fluid has only been studied in asthma, ${ }^{25}$ cystic fibrosis, ${ }^{26}$ and acute respiratory distress syndrome. ${ }^{27}$ In the BAL fluid of acute respiratory distress syndrome patients, a significant portion of the total glutathione is in the oxidised form (GSSG), which is likely to be due to the rapid extracellular oxidation of glutathione. ${ }^{27}$

Although the regulation of glutathione in BAL fluid is poorly understood, we speculate that GSSG accumulates in
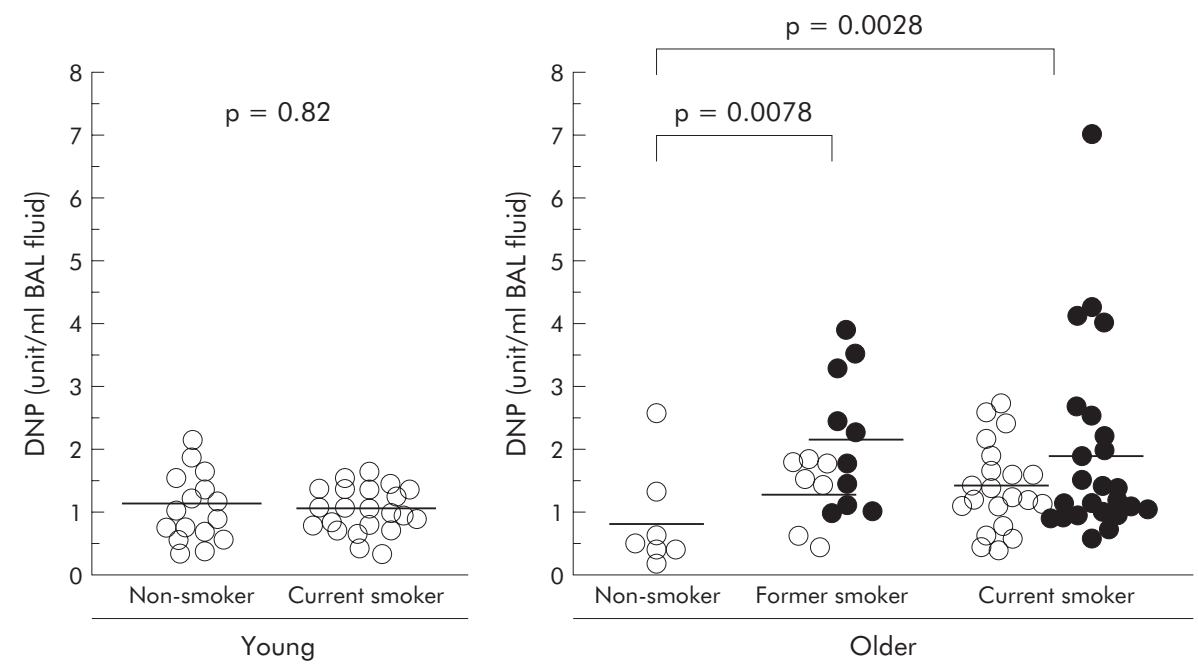

Figure 3 Total DNP units/ml in BAL fluid. Horizontal lines represent mean values of each group. Open circles represent subjects without emphysema; closed circles represent subjects with emphysema. DNP, dinitrophenylhydrazine. 

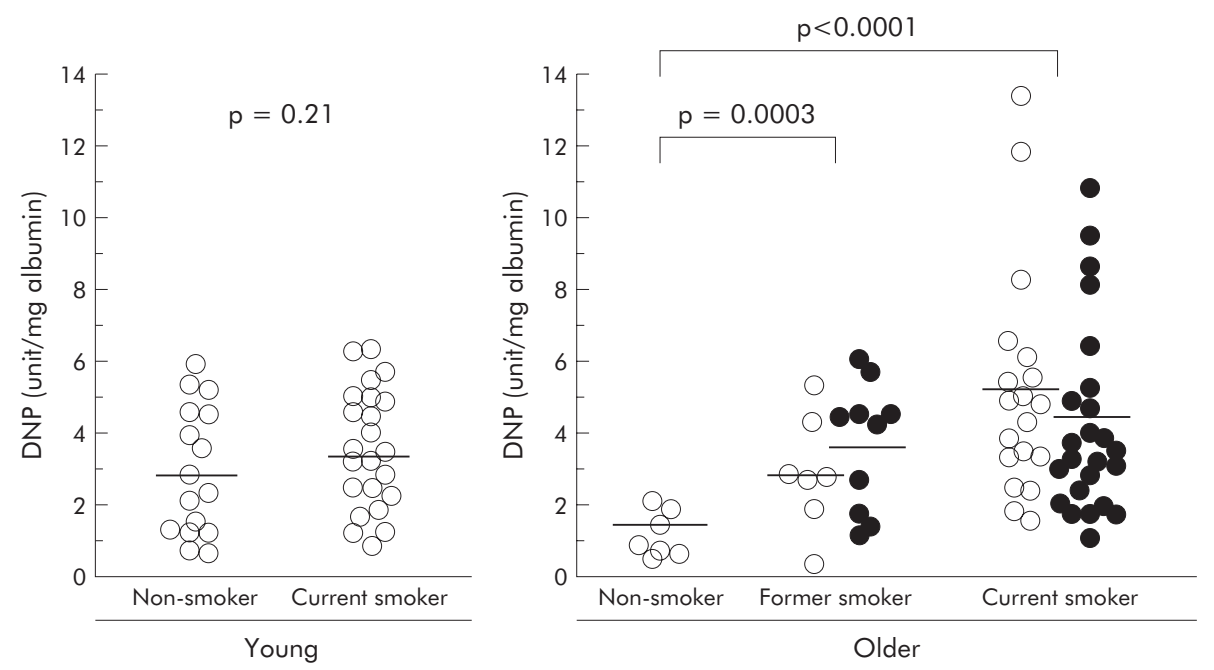

Figure 4 Carbonylated albumin/mg total albumin in BAL fluid. The horizontal lines represent mean values of each group. Open circles represent subjects without emphysema; closed circles represent subjects with emphysema. DNP, dinitrophenylhydrazine.

BAL fluid in older smokers by the following mechanisms. Firstly, the extracellular conversion of GSH into GSSG is accelerated as a result of excessive hydrogen peroxide generated in the ELF by extracellular glutathione peroxidase. Secondly, the efflux of GSSG from the lung cells is increased because of intracellular oxidative stress. Lung cells have many redox regulating enzymes and thiol containing proteins such as thioredoxins or peroxiredoxins that affect the intracellular GSSG/GSH balance. ${ }^{28-30}$ When the level of intracellular GSSG increases, the export might be accelerated by adenosine triphosphate binding cassette transporters such as multidrug resistant associated protein I (MRP I). ${ }^{31}$ Thirdly, extracellular GSSG catabolism might be impaired due to the attenuation of membrane bound $\gamma$-glutamyl transpeptidase activity. ${ }^{32}$ Fourthly, protein reactive thiols, which react with GSSG to release GSH, might be reduced in ELF leading to protein mixed disulfide synthesis. ${ }^{33}$ Taken together, it is likely that excessive oxidative stress in the lung is causally related to the high level of GSSG in BAL fluid.
Sampling of the ELF by BAL is a common means of studying proteins and investigating their changes in lung diseases. Because of the lack of an appropriate marker for the dilution of lavage fluids (to correct for variable recovery of epithelial lining fluid ${ }^{34}$ ), we decided not to normalise the data to albumin or urea. Instead, the data were expressed as the concentrations in the lavaged fluid as in our previous studies. $^{78}$ Despite the difference in the recovery rate of lavage fluid, the level of albumin in the BAL fluid did not differ between the groups (table 2). However, whether the variable rate of recovery may affect the results of comparisons between the groups cannot be determined.

The method and period of storage are also important for evaluating the oxidative status. We used frozen/preserved BAL fluid samples for the assays. Small aliquots of cell free supernatant of BAL fluid were made upon harvest and stored at $-70^{\circ} \mathrm{C}$ to avoid repeated freezing and thawing. It is difficult to directly validate the stability of BAL fluid stored for long periods, but we did not find a significant correlation
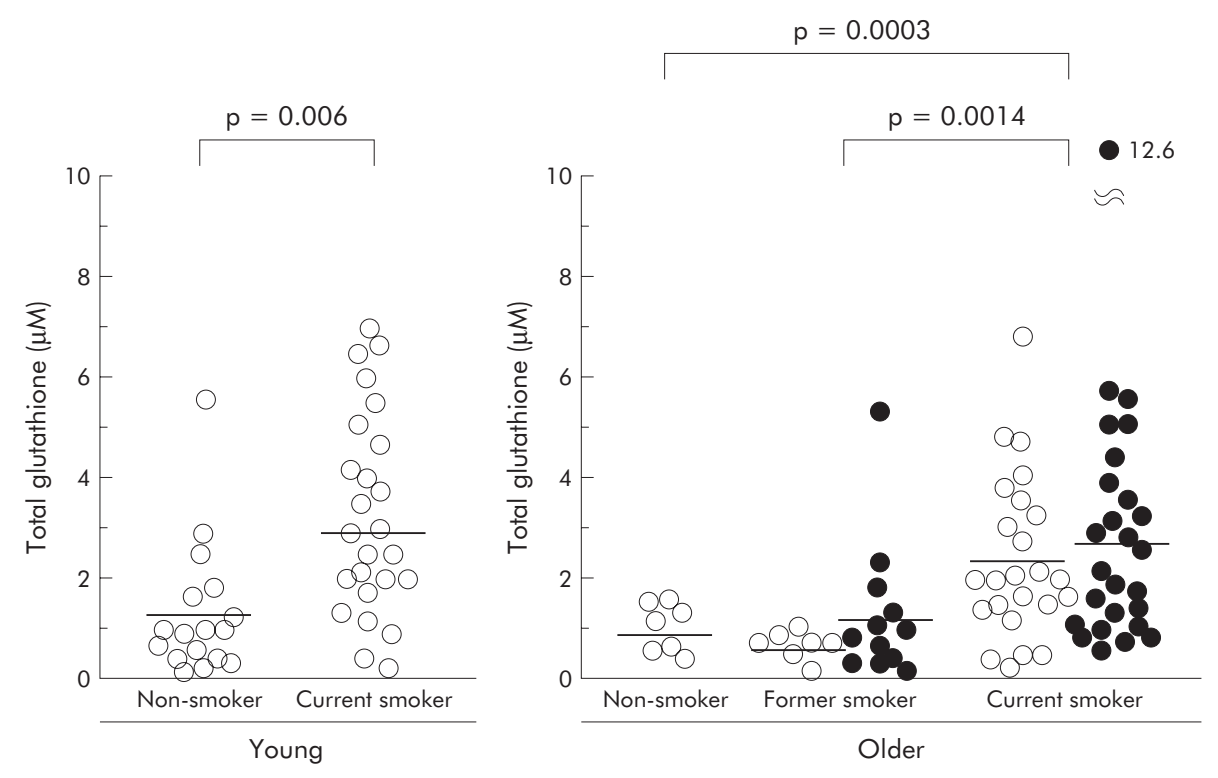

Figure 5 Levels of total glutathione in BAL fluid. The horizontal lines represent mean values of each group. Open circles represent subjects without emphysema; closed circles represent subjects with emphysema. 


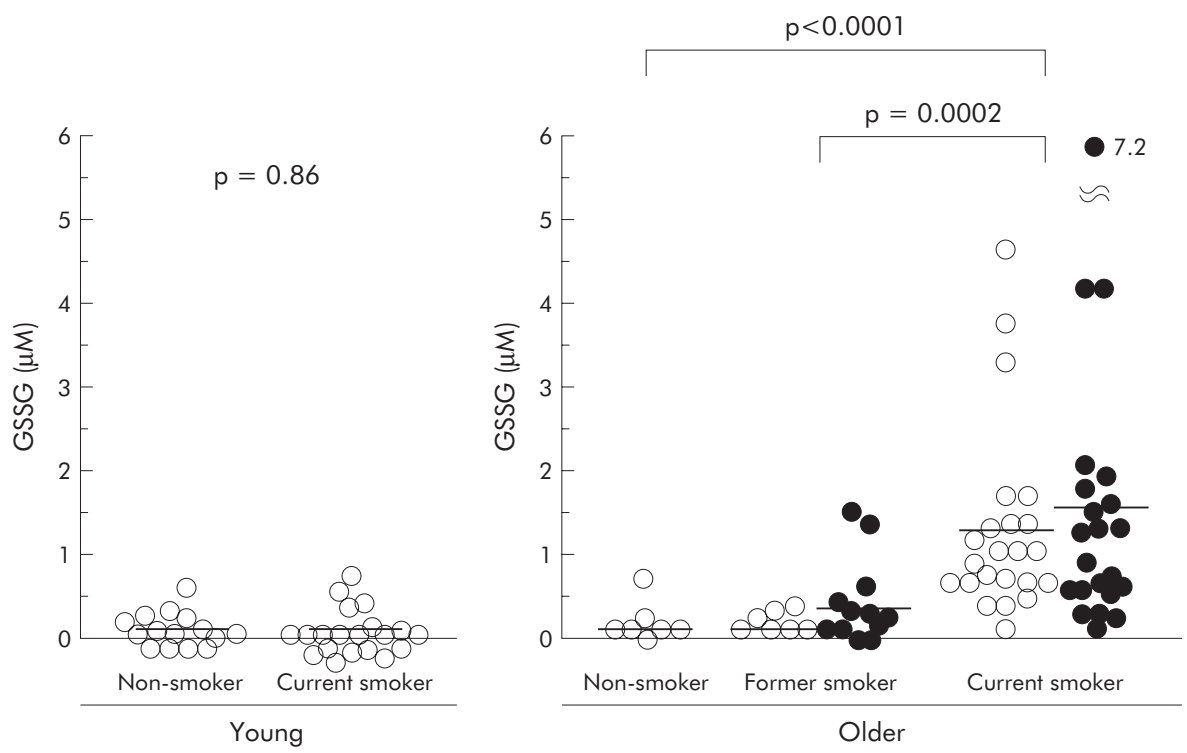

Figure 6 Levels of glutathione disulfide (GSSG) in BAL fluid. The horizontal lines represent mean values of each group. Open circles represent subjects without emphysema; closed circles represent subjects with emphysema.

between storage periods ( $1-11$ years) and the values for each assay for older current smokers (for carbonylated albumin, $\mathrm{n}=40, \mathrm{p}=0.73$; for GSSG, $\mathrm{n}=40, \mathrm{p}=0.65$ ). These results imply that markers of oxidative status such as GSSG and carbonylated albumin in BAL fluid are not directly affected by long term storage at $-70^{\circ} \mathrm{C}$.

This study clearly shows that the effects of smoking on the extracellular redox system differ with age between recent and long term smokers. It should be noted that older smokers are exposed to cigarette smoke over the years while concurrently ageing. Following smoking, the content of glutathione and the ratio of GSH to total glutathione in the whole lung are significantly lower in senescence accelerated mice than in senescence resistant mice. ${ }^{35}$ In humans, long term smoking leads to age related decreases in antioxidant activity in alveolar macrophages. ${ }^{36}$ We also recently reported a decrease with age in surfactant proteins A and D in the BAL fluid of long term smokers compared with age matched nonsmokers, whereas such differences were not observed among young subjects. ${ }^{7}$ Increases in several markers of oxidative stress have been reportedly linked to pulmonary diseases such as chronic obstructive pulmonary disease. ${ }^{14}{ }^{37-39}$ It is still not clear whether oxidative stress plays a direct role in the pathogenesis of chronic obstructive pulmonary disease or whether there is more oxidative stress as a result of ageing with long term chronic smoking. To address this issue, we first evaluated oxidative stress and glutathione redox status in BAL fluids collected from more than 100 subjects classified by age, smoking status, and the presence of mild emphysema in this study.

Although we did not observe a significant enhancement associated with the presence of emphysema according to CT scans, it should be noted that the severity of emphysema was classified as low and that the distribution was heterogeneous even in the older smokers classified as having emphysema. We cannot therefore rule out the possibility that the protein carbonyls and/or GSSG might be higher in BAL fluid from individuals with more advanced stages of emphysema.
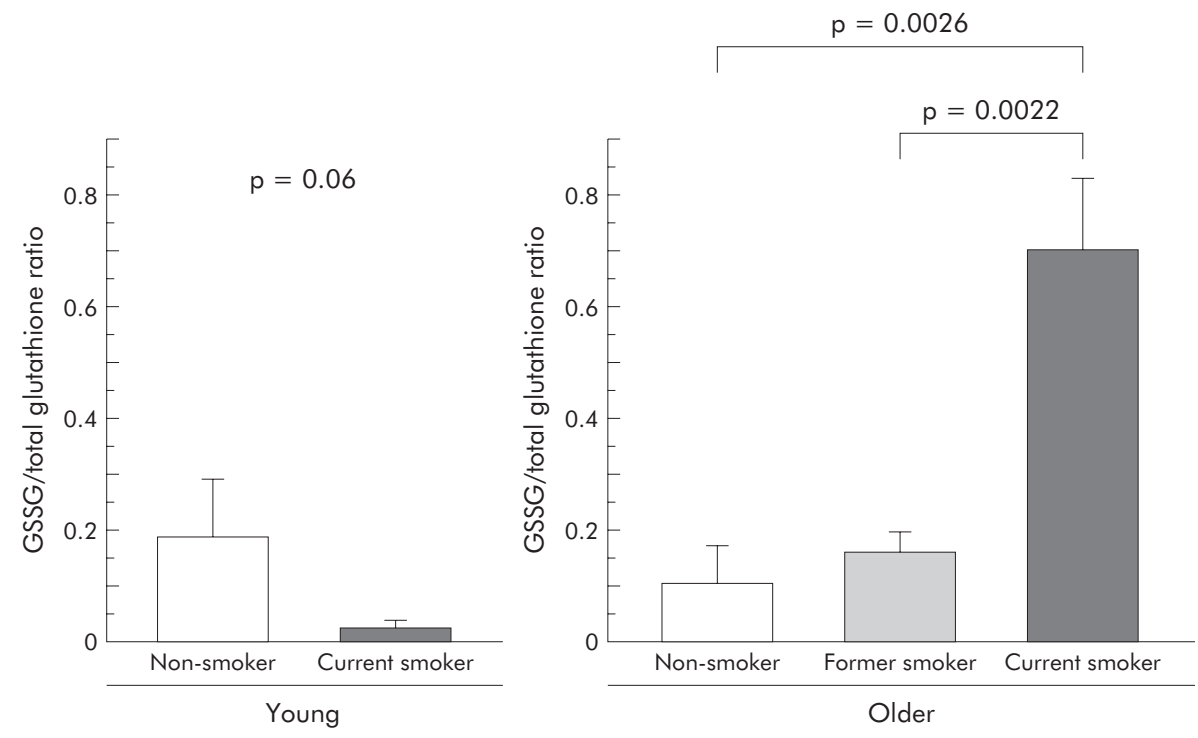

Figure 7 Glutathione disulfide (GSSG)/total glutathione ratio in BAL fluid. Data are mean (SE) values for each group. 
Although smoking related diseases are often found in older individuals, it is important to keep in mind that the extracellular antioxidant systems in the lungs of older people have an impaired ability to resist damage from cigarette smoke. Further studies will investigate the functions of GSSG and oxidised proteins in BAL fluid and the potential benefits of antioxidant supplementation for middle aged or elderly smokers.

\section{Authors' affiliations}

K Nagai, T Betsuyaku, Y Nasuhara, M Nishimura, First Department of Medicine, Hokkaido University School of Medicine, Sapporo, Japan

T Kondo, Nagasaki University Graduate School of Biomedical Sciences, Nagasaki, Japan

This research was supported by the Respiratory Failure Research Group of the Ministry of Health, Labor, and Welfare of Japan and scientific research grants from the Ministry of Education, Science, Culture and Sports of Japan (13470125 to MN and 14570532 to TB).

Competing interests: none declared.

\section{REFERENCES}

1 Mudway IS, Kelly FJ. Modeling the interactions of ozone with pulmonary epithelial lining fluid antioxidants. Toxicol Appl Pharmacol 1998;148:91-100.

2 Davies KJ. Protein damage and degradation by oxygen radicals. I. General aspects. J Biol Chem 1987;262:9895-901.

3 Dalle-Donne I, Giustarini D, Colombo R, et al. Protein carbonylation in human diseases. Trends Mol Med 2003;9:169-76.

4 Rahman I, MacNee W. Lung glutathione and oxidative stress: implications in cigarette smoke-induced airway disease. Am J Physiol 1999;277:L1067-88.

5 Cantin AM, North SL, Hubbard RC, et al. Normal alveolar epithelial lining fluid contains high levels of glutathione. J Appl Physiol 1987;63:152-7.

6 MacNee W, Rahman I. Is oxidative stress central to the pathogenesis of chronic obstructive pulmonary disease? Trends Mol Med 2001;7:55-62.

7 Betsuyaku T, Kuroki Y, Nagai K, et al. Effects of ageing and smoking on SP-A and SP-D levels in bronchoalveolar lavage fluid. Eur Respir J 2004; 24:964-70

8 Nagai K, Betsuyaku T, Ito $Y$, et al. Decrease of vascular endothelial growth factor in macrophages from long-term smokers. Eur Respir J 2005; 25:626-33.

9 Yoshioka A, Betsuyaku T, Nishimura M, et al. Excessive neutrophil elastase in bronchoalveolar lavage fluid in subclinical emphysema. Am J Respir Crit Care Med 1995;152:2127-32

10 Berglund E, Birath G, Bjure J, et al. Spirometric studies in normal subjects. I. Forced expirograms in subjects between 7 and 70 years of age. Acta Med Scand 1963;173:185-91.

11 Shacter E, Williams JA, Lim M, et al. Differential susceptibility of plasma proteins to oxidative modification: examination by western blot immunoassay. Free Radic Biol Med 1994;17:429-37.

12 Tietze F. Enzymic method for quantitative determination of nanogram amounts of total and oxidized glutathione: applications to mammalian blood and other tissues. Anal Biochem 1969;27:502-22.

13 Altuntas I, Dane S, Gumustekin K. Effects of cigarette smoking on lipid peroxidation. J Basic Clin Physiol Pharmacol 2002;13:69-72.

14 Rahman I, van Schadewijk AA, Crowther AJ, et al. 4-Hydroxy-2-nonenal, a specific lipid peroxidation product, is elevated in lungs of patients with chronic obstructive pulmonary disease. Am J Respir Crit Care Med 2002;166:490-5.
15 Lenz AG, Jorens PG, Meyer B, et al. Oxidatively modified proteins in bronchoalveolar lavage fluid of patients with ARDS and patients at-risk for ARDS. Eur Respir J 1999;13:169-74.

16 Lenz AG, Costabel U, Maier KL. Oxidized BAL fluid proteins in patients with interstitial lung diseases. Eur Respir J 1996;9:307-12.

17 Kettle AJ, Chan T, Osberg I, et al. Myeloperoxidase and protein oxidation in the airways of young children with cystic fibrosis. Am J Respir Crit Care Med 2004; 170:1317-23.

18 Jana CK, Das N, Sohal RS. Specificity of age-related carbonylation of plasma proteins in the mouse and rat. Arch Biochem Biophys 2002;397:433-9.

19 Himmelfarb J, McMonagle E. Albumin is the major plasma protein target of oxidant stress in uremia. Kidney Int 2001;60:358-63.

20 Pignatelli B, Li CQ, Boffetta $P$, et al. Nitrated and oxidized plasma proteins in smokers and lung cancer patients. Cancer Res 2001;61:778-84.

21 Choi J, Malakowsky CA, Talent JM, et al. Identification of oxidized plasma proteins in Alzheimer's disease. Biochem Biophys Res Commun 2002;293:1566-70

22 Bourdon E, Loreau N, Blache D. Glucose and free radicals impair the antioxidant properties of serum albumin. FASEB J 1999;13:233-44.

23 Jain A, Martensson J, Mehta T, et al. Ascorbic acid prevents oxidative stress in glutathione-deficient mice: effects on lung type 2 cell lamellar bodies, lung surfactant, and skeletal muscle. Proc Natl Acad Sci USA 1992;89:5093-7.

24 Cross CE, O'Neill CA, Reznick AZ, et al. Cigarette smoke oxidation of human plasma constituents. Ann NY Acad Sci 1993;686:72-89.

25 Kelly FJ, Mudway I, Blomberg A, et al. Altered lung antioxidant status in patients with mild asthma. Lancet 1999;354:482-3.

26 Dauletbaev N, Viel K, Buhl R, et al. Glutathione and glutathione peroxidase in sputum samples of adult patients with cystic fibrosis. J Cyst Fibros 2004:3:119-24.

27 Bunnell E, Pacht ER. Oxidized glutathione is increased in the alveolar fluid of patients with the adult respiratory distress syndrome. Am Rev Respir Dis 1993;148:1174-8.

28 Dickinson DA, Forman HJ. Cellular glutathione and thiols metabolism. Biochem Pharmacol 2002;64:1019-26.

29 Holmgren A. Antioxidant function of thioredoxin and glutaredoxin systems Antioxid Redox Signal 2000;2:811-20.

30 Kinnula VL. Focus on antioxidant enzymes and antioxidant strategies in smoking related airway diseases. Thorax 2005;60:693-700.

31 van der Deen $M$, de Vries EG, Timens $W$, et al. ATP-binding cassette $(A B C)$ transporters in normal and pathological lung. Respir Res 2005;6:59-75.

32 Paolicchi A, Lorenzini E, Perego P, et al. Extracellular thiol metabolism in clones of human metastatic melanoma with different gamma-glutamyl transpeptidase expression: implications for cell response to platinum-based drugs. Int J Cancer 2002;97:740-5.

33 Thomas JA, Poland B, Honzatko R. Protein sulfhydryls and their role in the antioxidant function of protein S-thiolation. Arch Biochem Biophys 1995;319:1-9.

34 Marcy TW, Merrill WW, Rankin JA, et al. Limitations of using urea to quantify epithelial lining fluid recovered by bronchoalveolar lavage. Am Rev Respir Dis 1987; 135:1276-80.

35 Uejima Y, Fukuchi Y, Nagase T, et al. Influences of inhaled tobacco smoke on the senescence accelerated mouse (SAM). Eur Respir J 1990;3:1029-36.

36 Kondo T, Tagami S, Yoshioka A, et al. Current smoking of elderly men reduces antioxidants in alveolar macrophages. Am J Respir Crit Care Med 1994; 149:178-82

37 Pratico D, Basili S, Vieri M, et al. Chronic obstructive pulmonary disease is associated with an increase in urinary levels of isoprostane F2alpha-III, an index of oxidant stress. Am J Respir Crit Care Med 1998; 158:1709-14.

38 Paredi P, Kharitonov SA, Leak D, et al. Exhaled ethane, a marker of lipid peroxidation, is elevated in chronic obstructive pulmonary disease. Am J Respir Crit Care Med 2000;162:369-73.

39 Drost EM, Skwarski KM, Sauleda J, et al. Oxidative stress and airway inflammation in severe exacerbations of COPD. Thorax 2005;60:293-300. 